\title{
Nutritional Status of Preterm Neonates at Discharge in Sanglah Hospital
}

\author{
CrossMark \\ I Made Samitha Wijaya ${ }^{a}$, Made Sukmawati ${ }^{b}$, Putu Junara Putrac, I Made Kardana ${ }^{\mathrm{d}}$, I Wayan Dharma \\ Artana $^{\mathrm{e}}$
}

Manuscript submitted: 27 July 2020, Manuscript revised: 09 August 2020, Accepted for publication: 18 September 2020

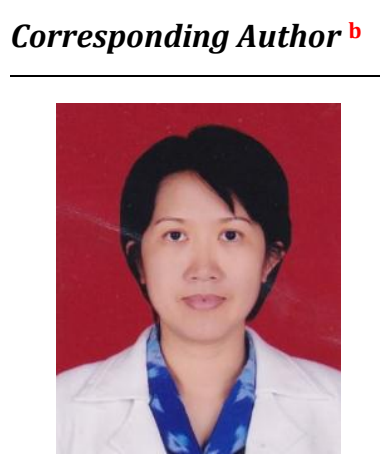

Keywords

child;

hospital;

neonates;

nutritional status;

preterm;

\begin{abstract}
The purpose of this study was to determine the nutritional status of preterm neonates when discharged from the hospital. A descriptive study was reviewed from the register of preterm neonate after hospitalization in neonatal ward Sanglah Hospital Denpasar. The number of total samples in this study was 190 patients. Most of the preterm neonates in this study were low birth weight (59.47\%). At the beginning of the hospitalization, there were $83.86 \%$ preterm neonates with good nutritional status, decreased to $54.73 \%$ at discharge from the hospital. The group of neonates that had the highest number of decreases in the good nutritional status at discharge was found in 28-32 weeks gestational age. Most of the samples used breast milk for enteral feeding $(68,42 \%)$. In preterm neonates with sepsis, only $42.52 \%$ neonates discharge with good nutritional status. Low birth weight preterm neonates with kangaroo method care were found increased weight gain in $78.57 \%$ neonates. The nutritional status of preterm neonates following hospitalization at Sanglah hospital is still not good. The preterm neonates with good nutritional status were decreased at discharge from the hospital. The enteral nutrition, gestational age, length of stay, comorbidities, and kangaroo method care were affected nutritional status in preterm neonates at Sanglah hospital.
\end{abstract}

International Journal of Health Sciences (C) 2020.

This is an open access article under the CC BY-NC-ND license (https://creativecommons.org/licenses/by-nc-nd/4.0/).

\section{Contents}

Abstract

1 Introduction

2 Materials and Methods.

3 Results and Discussions

a Department of Child Health, Medical Faculty, Udayana University and Department of Child Health, Sanglah Hospital, Denpasar, Indonesia

b Department of Child Health, Medical Faculty, Udayana University and Department of Child Health, Sanglah Hospital, Denpasar, Indonesia

c Department of Child Health, Medical Faculty, Udayana University and Department of Child Health, Sanglah Hospital, Denpasar, Indonesia

d Department of Child Health, Medical Faculty, Udayana University and Department of Child Health, Sanglah Hospital, Denpasar, Indonesia

e Department of Child Health, Medical Faculty, Udayana University and Department of Child Health, Sanglah Hospital, Denpasar, Indonesia 


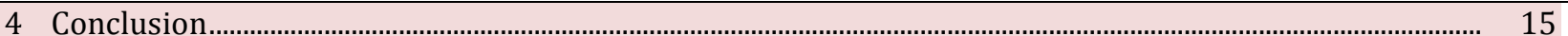

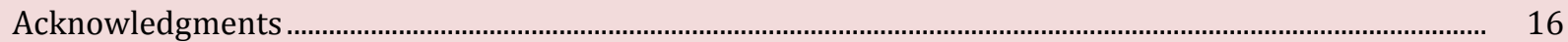

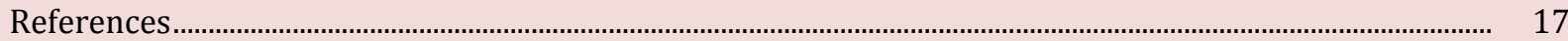

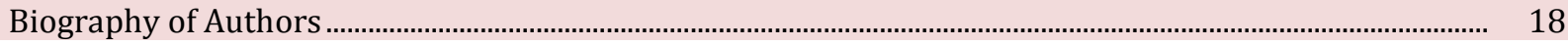

\section{Introduction}

The first thousand days of life are periods that determine a child's growth and development. Experts say this period is a golden period. Most children are fortunate to get through this golden period well, born normal with sufficient weight and healthy. But some children are not born this lucky (Rani, 2017). They are born earlier, with bodyweight far below normal suffering from abnormalities, and require treatment in the hospital.

Providing adequate nutrition during infancy is very important so that the baby's growth will be optimal. Monitoring nutritional status while in the nursery is needed to know whether the optimal growth is reached. Monitoring baby's weight during treatment is very important to achieve ideal body weight so that malnutrition does not occur. Providing adequate nutrition is important in premature neonates to achieve ideal growth. Neonate weight gain of 15 grams $/ \mathrm{kg} /$ day was said to be a good threshold (Fenton et al., 2018; IDAI, 2016). It was found that only $12.98 \%$ of neonates increased in body weight more than $15 \mathrm{grams} / \mathrm{kg} / \mathrm{day}$ during treatment in the hospital. Neonate with an increment of body weight less than $15 \mathrm{grams} / \mathrm{kg} / \mathrm{day}$ are increased risk of growth and neurodevelopmental problems in the future (IDAI, 2016).

Numerous data shows that hospitalization is putting the neonate at risk for poor nutritional status once they are discharged (Namiro et al., 2012). The baby's weight gain data during treatment can provide information about the growth of the neonates and provide alertness to medical personnel and parents. This data is useful in improving hospital services. Until now, there is no data on nutritional status in preterm neonates in Sanglah hospital. The purpose of this study was to determine the nutritional status of preterm neonates when discharged from the hospital and to know the nutritional status based on enteral nutrition, gestational age, length of stay, morbidities, and kangaroo method care (Tang et al., 1994; Manzoni et al., 2013).

\section{Materials and Methods}

This study was descriptive. We retrospectively reviewed the register of preterm neonate after hospitalization in neonatal ward Sanglah Hospital Denpasar from January 2018 to December 2018. The inclusion criteria were preterm neonates who were treated in the neonatal ward Sanglah Hospital Denpasar. The exclusion criteria were incomplete medical records or insufficient data. Samples were selected using the consecutive sampling technique. Sample size calculated with formula $n=N /\left(1+N\left(d^{2}\right)\right)$, the result was 137 sample. The number of total samples in this study was 190 patients.

The data of each patient was taken in the form of age, gender, gestational age, delivery method, birth weight, bodyweight at discharge, duration of treatment, type of enteral nutrition, and nutritional status at discharge according to the Fenton curve (Flancbaum et al., 2006; Gonzalez-Castro et al., 2006). The definition of operational variables was:

a) Age is the time at birth until discharge from neonatal ward Sanglah Hospital. Age is expressed in days.

b) Gender is a morphological appearance, either of the sexes (male and female). Gender divided into male and female

c) Gestational age is the time elapsed between the first day of the last menstrual period (LMP) and the day of delivery. In this study, gestational age was assessed by examination of physical and neuromuscular maturity based on the New Ballard score and expressed in weeks.

d) Method of delivery is the process of delivering baby and placenta, membranes, and umbilical cord from the uterus-the method of delivery divided into cesarean section (surgical procedure) and spontaneous (vaginal delivery).

e) Birth weight is the baby's weight at birth, expressed in grams.

Wijaya, I. M. S., Sukmawati, M., Putra, P. J., Kardana, I. M., \& Artana, I. W. D. (2020). Nutritional status of preterm neonates at discharge in sanglah hospital. International Journal of Health Sciences, 4(3), 10-19. https://doi.org/10.29332/ijhs.v4n3.449 
f) Bodyweight at discharge is the baby's weight when discharge from the neonatal ward, expressed in grams.

g) The duration of treatment is the length of stay since admission until discharge from the neonatal ward, expressed in days.

h) Type of enteral nutrition is the type of enteral feeding during treatment, are categorized into breast milk, the combination of breast milk + human milk fortification (HMF), standard formula milk, premature formula milk, and combination of the breast milk \& formula milk.

i) Nutritional status is a nutritional assessment based on anthropometric measurements using the Fenton curve and described into a percentile. Undernourished is the baby's weight less than the P10 ${ }^{\text {th }}$ of the Fenton curve. Good nutritional status when the baby's weight between P10 ${ }^{\text {th }}-\mathrm{P} 90^{\text {th }}$.

j) Ideal weight gain is weight gain during treatment of more than 15 grams $/ \mathrm{kg} /$ day. Calculated from total weight gain during hospitalization divided by the length of stay.

The samples were collected from the obtained data, then processed with a computer program. The research was conducted after approval of the Ethics Committee of Medical Faculty of Medicine/Sanglah Hospital.

\section{Results and Discussions}

Amount of 964 neonates were treated at Sanglah Hospital in 2018, and the number of premature neonates was 267 (27.69\%), with 59 (22.09\%) of them did not survive during treatment. Of the 208 patients, there were 18 patients with incomplete data, so the total subjects were 190 neonates. Most of the premature neonates who were born at Sanglah Hospital during 2018, were low birth weight neonates $(1500-<2500$ gram), as many as 113 neonates (59.47\%), as shown in table 1.

This study found the median length of stay of neonates was 16 days, the average birth weight was 1893 grams, and the median of bodyweight at discharge was 2035 grams. At the beginning of the hospitalization, there were 159 premature neonates with good nutritional status. During treatment in the nursery, there was a reduction in the good nutritional status where well-nourished was found in $159(83.68 \%)$ neonates at the beginning of treatment, decreased to 104 (54.73\%) at discharge from hospital, as seen in figure 1 . The total number of preterm neonates who gained weight during treatment was 135 (71.05\%) neonates, but only 20 $(14.81 \%)$ of the neonates increased ideal weight gain.

Table 1

Characteristics of the samples

\begin{tabular}{ll}
\hline Characteristics & $\mathrm{n}(\%)$ \\
\hline Gender & $107(56.3)$ \\
$\quad$ Males & $83(43.7)$ \\
$\quad$ Female & \\
Gestational age & $3(1.6)$ \\
$\quad<28$ week & $43(22.6)$ \\
28-32 week & $144(75.8)$ \\
>32- <37 week & \\
Delivery method & $86(45.3)$ \\
Spontaneous & $104(54.7)$ \\
Sectio Caesaria & \\
Birthweight & $30(15.79)$ \\
$\quad>2500$ gram & $113(59.47)$ \\
1500 - <2500 gram & $45(23.69)$ \\
1000 - <1500 gram & $2(1.05)$ \\
<1000 gram & \\
Enteral nutrition & $90(47.4)$ \\
Breast milk &
\end{tabular}




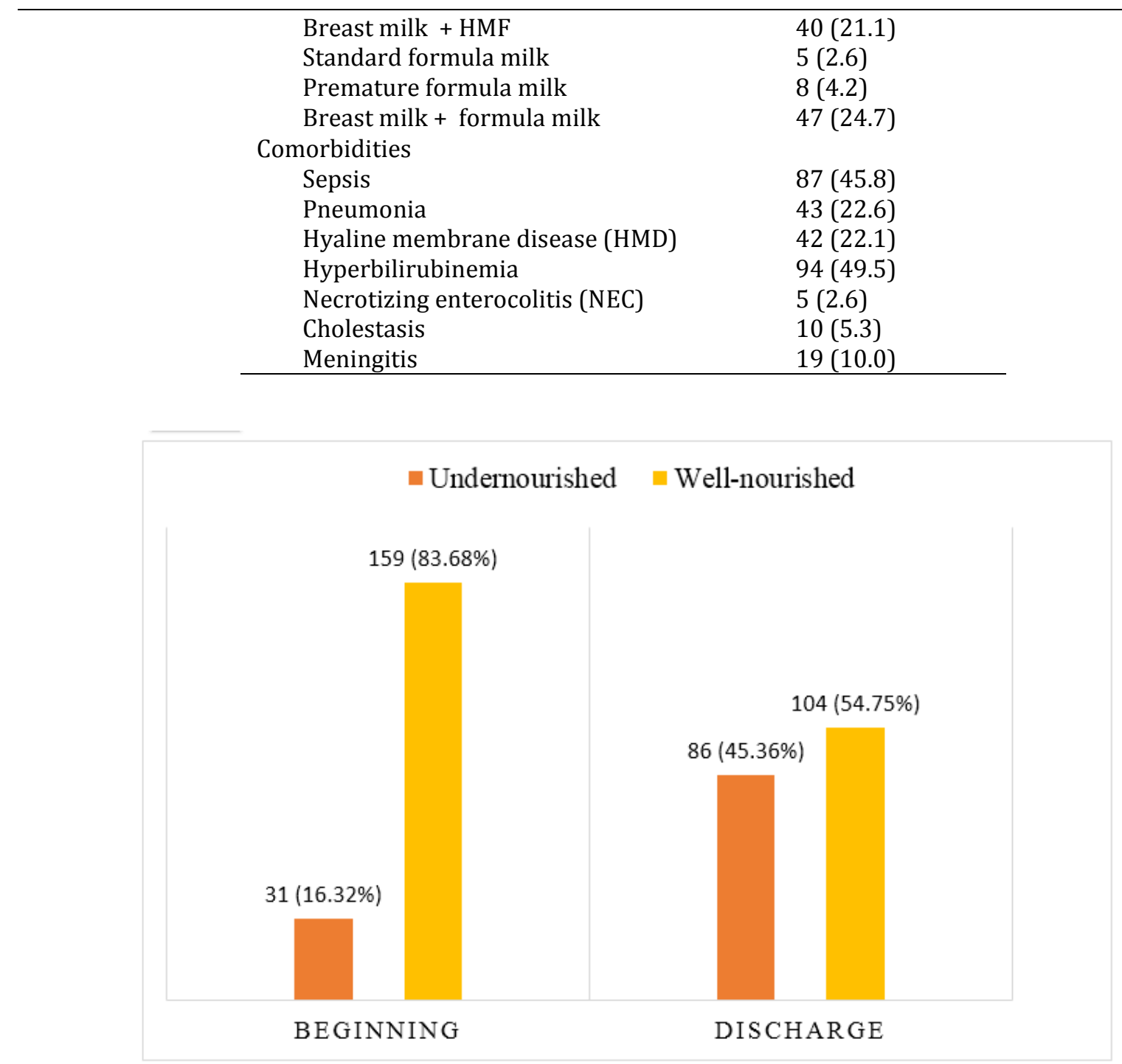

Figure 1. The nutritional status at the beginning of hospitalization and discharge

The group of neonates that had the highest number of decrease in the good nutritional status at discharge was found in 28-32 weeks gestational age, decrease from $95.34 \%$ to $44.18 \%$. The description of the length of stay, weight gain, and nutritional status according to the gestational age was described in table 2 .

Table 2

Length of stay, weight gain, and nutritional status according to gestational age

\begin{tabular}{llllll}
\hline Gestational age & $\begin{array}{l}\text { Length of } \\
\text { stay (days) }\end{array}$ & $\begin{array}{l}\text { Total number } \\
\text { of premature } \\
\text { neonates }\end{array}$ & $\begin{array}{l}\text { Good nutritional } \\
\text { status at birth } \\
\mathrm{n}(\%)\end{array}$ & $\begin{array}{l}\text { Good nutritional } \\
\text { status at discharge } \\
\mathrm{n}(\%)\end{array}$ & $\begin{array}{l}\text { Weight gain } \\
\text { median (gram) }\end{array}$ \\
\hline$<28$ week & $59(51-63)$ & 3 & $3(100)$ & $3(100)$ & $990(960-1115)$ \\
$28-32$ week & $28(4-107)$ & 43 & $41(95.34)$ & $19(44.18)$ & $250((-50)-1700)$ \\
$>32-<37$ week & $11(2-79)$ & 144 & $115(79.86)$ & $104(72.22)$ & $50((-310)-1730)$ \\
\hline
\end{tabular}

Wijaya, I. M. S., Sukmawati, M., Putra, P. J., Kardana, I. M., \& Artana, I. W. D. (2020). Nutritional status of preterm neonates at discharge in sanglah hospital. International Journal of Health Sciences, 4(3), 10-19. https://doi.org/10.29332/ijhs.v4n3.449 
This study showed that breast milk was the most widely used for enteral feeding in preterm neonates in Sanglah hospital in 130 (68.42\%) neonates, and 40 (30.76\%) of them used breast milk with Human Milk Fortifier (HMF). The type of enteral nutrition and nutritional status at discharge is described in table 3.

Table 3

Type of enteral nutrition and nutritional status at discharge

\begin{tabular}{llll}
\hline Enteral nutrition & $\begin{array}{l}\text { Number of neonates } \\
\mathrm{n}(\%)\end{array}$ & $\begin{array}{l}\text { Good nutritional } \\
\text { status at discharge } \\
\mathrm{n}(\%)\end{array}$ & $\begin{array}{l}\text { Ideal weight gain } \\
\mathrm{n}(\%)\end{array}$ \\
\hline Breast milk & $90(47.4)$ & $55(61.11)$ & $7(7.78)$ \\
Breast milk + HMF & $40(21.1)$ & $14(35.0)$ & $7(17.5)$ \\
Standard formula milk & $5(2.6)$ & $2(40.0)$ & 0 \\
Premature formula milk & $8(4.2)$ & $3(37.5)$ & $2(25.0)$ \\
Breast milk + formula milk & $47(24.7)$ & $30(63.83)$ & $4(8.51)$ \\
\hline
\end{tabular}

The characteristics of the disease during treatment, as described in table 1 , showed that the comorbidities were hyperbilirubinemia 94 (49.47\%) followed by sepsis, found in 87 (45.78\%), neonates. The neonate with sepsis was found out to experience more weight loss compared to the neonate with no sepsis, as seen in figure 2.

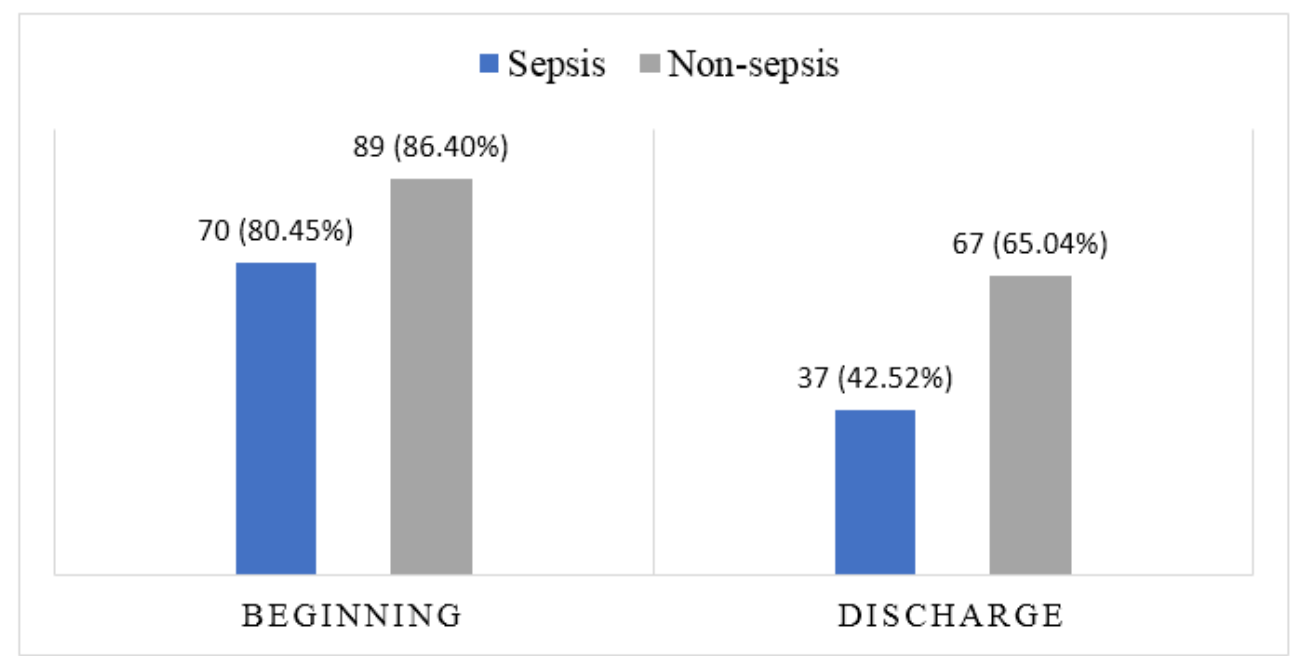

Figure 2. The good nutritional status of sepsis neonates at the beginning of hospitalization and discharge

Kangaroo mother care (KMC) is a supportive therapy in supporting premature neonates, where KCM helps increasing the neonatal weight by reducing stress hormones and make the neonates more stable. In this study, we found $50(26.3 \%)$ preterm neonates had a KMC. Based on low birth weight, we found 22 (78.57\%) neonates with KMC increased their body weight at discharge and the ideal weight gain was found in 3 $(10.71 \%)$ neonates, as shown in table 4.

Table 4

Increased bodyweight \& ideal weight gain of KMC and conventional therapy on LBW neonates

\begin{tabular}{llll}
\hline Supportive therapy & $\begin{array}{l}\text { Number of neonates } \\
\mathrm{n}(\%)\end{array}$ & $\begin{array}{l}\text { Increased body } \\
\text { weight at discharge } \\
\mathrm{n}(\%)\end{array}$ & $\begin{array}{l}\text { Ideal weight gain } \\
\mathrm{n}(\%)\end{array}$ \\
\hline KMC & $28(24.78)$ & $22(78.57)$ & $3(10.71)$ \\
Conventional & $85(75.22)$ & $54(63.52)$ & $6(7.06)$ \\
\hline
\end{tabular}


Discussion

The incidence of preterm birth is different in every country in the world. The incidence of preterm birth in the USA based on 2008 National Vital Statistics data was 12.6\%, in the United Kingdom was 10\% (2004-2005), in India was 20.9\% (2007) (Bibby \& Stewart, 2004; Uma et al., 2007). Based on the data from WHO in 2018, the incidence of premature neonates in Indonesia was $14.05 \%$. In this study, we found that the number of premature neonates being treated in Sanglah Hospital in 2018 was 267 neonates, which was $27.69 \%$ of total neonates treated.

In a study by Ananya D in 2015 that the incidence of preterm birth was $10.23 \%$, with $80.8 \%$ of premature neonates were between 32-37 weeks' gestational age (Das et al., 2015). Most of the preterm neonate's birth weight was found in the range of low birth weight (LBW) of 1500-2500 grams (71.5\%) (Das et al., 2015). The results are similar to our study that the gestational age of premature neonates treated at Sanglah Hospital was mostly above 32 weeks' gestation and $59.47 \%$ of neonates with birth weight between $1500-<2500$ gram.

Providing good nutrition during the treatment of preterm neonates is very important. This will reduce mortality and morbidity and prevent growth and development disturbance in the future. Many data show that preterm neonates do not experience a good increment of bodyweight during treatment at the hospital. Our study shows that during hospitalization, preterm neonates with good nutritional status were decreased from $159(83.68 \%)$ to $104(54.75 \%)$, and undernourished neonates were increased from 31 (16.32\%) to 86 (45.36\%) at discharge. Compared to another study by Fenton in 2013, in Calgary, Regina and San Diego found the number of undernourished neonates was increased from $11 \%$ to $31 \%$ after two weeks of hospitalization (Fenton et al., 2013; Hintz et al., 2010; Lee et al., 2018; Maier et al., 2018). The inadequate improvement of nutritional status in the preterm neonates due to multifactorial, including nutritional support during treatment, the morbidity of preterm neonates, and complex interactions of genetic and environmental (Martins-Celeni et al., 2018).

Some factors affect the care of preterm neonates in hospitals, including gestational age, disease conditions, infections, nutritional management, surgery, respiratory distress, and oxygen management (Seaton et al., 2016). Namiro et al. (2012), found that $48.1 \%(113 / 235)$ of low birth weight neonates had not regained their birth weight by 21 days of hospital stay, the highest was found at gestational age $>32$ weeks by $56.6 \%$ (Namiro et al., 2012). In our study, we found premature neonates in 28-<32 weeks gestational age only $44.18 \%$ discharge in good nutritional status and $>32-<37$ weeks gestation at $72.22 \%$, this could be because of the longer lengths of stay and a higher risk of mortality in $<32$ weeks gestational age. There were three neonates with gestational age $<28$ weeks with good nutritional status at discharge; this could be because of good nutrition given, respiratory distress, and disease management in the hospital.

Providing adequate nutrition during treatment is an important key in achieving ideal body weight. Nutrition can be given in the form of breast milk, breast milk in combination with HMF, or premature formula. The goal of providing nutrition in preterm neonates is to achieve weight gain suitable for intrauterine growth or ideal weight gain $15-20$ grams $/ \mathrm{kg} /$ day (IDAI, 2016). This study found that breast milk was the most enteral nutrition used in $130(68.42 \%)$ neonates, and $40(30.76 \%)$ of them used a combination of breast milk and HMF. The ideal weight gain was achieved in the preterm formula group (25\% of 8 neonates), followed by a combination of breast milk and HMF $17.5 \%$. These final results are similar to a study by Quigley M, Embleton ND, McGuire W in 2018, found the formula-fed neonates had higher in-hospital rates of weight gain (mean difference 2.51,95\% confidence interval 1.93 to $3.08 \mathrm{~g} / \mathrm{kg} /$ day) (Quigley, 2018). The policy in our unit is giving breast milk + HMF for preterm neonates with the weight under P50th according to Phenton curve and preterm formula milk if breast milk is not available. In this study, we found only 55(61.11\%), neonates, with breast milk discharge with good nutritional status. Some reasons why they did not use HMF: intolerance of HMF or the price of HMF.

Comorbidities of the preterm neonates also influence neonatal growth during treatment. Severe morbidity included bronchopulmonary dysplasia (BPD), necrotizing enterocolitis (NEC), severe neurological injury, and sepsis (Godeluck et al., 2019; AlJohani et al., 2020; Utomo, 2010). In this study, most of the preterm neonates were hospitalized due to hyperbilirubinemia, followed by sepsis. Metabolism is increased in sepsis condition due to the response to the inflammatory process and activation of the immune system. Also, in the preterm neonates, their intestinal barrier has not yet been appropriately formed, reduced immune response in the

Wijaya, I. M. S., Sukmawati, M., Putra, P. J., Kardana, I. M., \& Artana, I. W. D. (2020). Nutritional status of preterm neonates at discharge in sanglah hospital. International Journal of Health Sciences, 4(3), 10-19. https://doi.org/10.29332/ijhs.v4n3.449 
gastrointestinal tract, a change in intestinal microbes. This is associated with an increased incidence of NEC because it is associated with the loss of intestinal barrier function and bacterial translocation in the intestine (Freitas et al., 2011; Quigley et al., 2019). In this study, sepsis was found in 87 (45.78\%) neonates, and 5 $(2.6 \%)$ of them suffered NEC. In preterm neonates with sepsis, only 37 (42.52\%) neonates discharge with good nutritional status.

One method of baby care that supports premature neonate nutrition is the kangaroo method of care. Kangaroo mother care has an advantage in reducing stress hormones in neonates which makes the baby stable, faster weight gain, and initiates breastfeeding. In the study of Samra et al. (2013), there was a higher weight increase in patients who had KMC compared to conventional methods (22.09 vs. 10.39 grams/day, $\mathrm{p}<0.001$ ), and KMC provided positive results in weight gain in LBW neonates as additional interventions (Samra, 2013). Conde et al. (2011), in a review of sixteen studies with 2518 neonates, by looking at the nutritional status of KMC neonates compared to conventional care, concluded that KMC provides the benefits for weight gain in LBW neonates (Conde et al., 2011). The result of this study is similar to other previous studies that LBW neonates who performed KMC, was found that the weight gain increased by $78.57 \%$ neonates, higher than conventional ones of $63.52 \%$.

\section{Conclusion}

The nutritional status of preterm neonates following hospitalization at Sanglah hospital is still not good. The preterm neonates with good nutritional status were decreased from 159 (83.68\%) neonates at the beginning of treatment, decreased to 104 (54.75\%) at discharge from hospital. The enteral nutrition, gestational age, length of stay, comorbidities, and kangaroo method care (KMC) were affected nutrional status in preterm neonates at Sanglah hospital.

\section{Limitation of the study}

This study did not obtain any data of height and head circumference, which certainly supports the determination of the nutritional status of the baby during treatment. Further study is needed to know any relationship of gestational age, comorbidities of preterm neonates to nutritional status at discharge from the hospital.

\section{Acknowledgments}

We are grateful to two anonymous reviewers for their valuable comments on the earlier version of this paper. 


\section{References}

AlJohani, E., Qaraqei, M., \& Al-Matary, A. (2020). Estimating the neonatal length of stay for preterm babies in a saudi tertiary hospital. Journal of Clinical Neonatology, 9(1), 13.

Bibby, E., \& Stewart, A. (2004). The epidemiology of preterm birth. Neuro endocrinology letters, 25, 43. https://doi.org/10.1186/1471-2393-13-23

Conde, A.A., Belizán, J.M., \& Diaz, R.J. (2011). Kangaroo mother care to reduce morbidity and mortality in low birth weight infants (Review). The Cochrane Collaboration.3, 1-120.

Das, A., Panda, S., Ahanthem, Sourabh, Pratap B. (2015). Preterm Birth: Analysis of Risk Factors and Neonatal Outcome. iMedPub J. 1(1), 1-5.

Fenton, T. R., Anderson, D., Groh-Wargo, S., Hoyos, A., Ehrenkranz, R. A., \& Senterre, T. (2018). An attempt to standardize the calculation of growth velocity of preterm infants-evaluation of practical bedside methods. The Journal of Pediatrics, 196, 77-83. https://doi.org/10.1016/j.jpeds.2017.10.005

Fenton, T. R., Nasser, R., Eliasziw, M., Kim, J. H., Bilan, D., \& Sauve, R. (2013). Validating the weight gain of preterm infants between the reference growth curve of the fetus and the term infant. BMC pediatrics, 13(1), 92.

Flancbaum, L., Belsley, S., Drake, V., Colarusso, T., \& Tayler, E. (2006). Preoperative nutritional status of patients undergoing Roux-en-Y gastric bypass for morbid obesity. Journal of Gastrointestinal Surgery, 10(7), 1033-1037. https://doi.org/10.1016/j.gassur.2006.03.004

Freitas, R. T. L., Gomes, A. P., \& Siqueira-Batista, R. (2011). Nutrition therapy and neonatal sepsis. Rev Bras Ter Intensiva, 23(4), 492-498.

Godeluck, A., Gérardin, P., Lenclume, V., Mussard, C., Robillard, P. Y., Sampériz, S., ... \& Ramful, D. (2019). Mortality and severe morbidity of very preterm infants: comparison of two French cohort studies. BMC pediatrics, 19(1), 360. https://doi.org/10.1186/s12887-019-1700-7

Gonzalez-Castro, A., Llorca, J., Suberviola, B., Diaz-Reganon, G., Ordonez, J., \& Minambres, E. (2006, October). Influence of nutritional status in lung transplant recipients. In Transplantation proceedings (Vol. 38, No. 8, pp. 2539-2540). Elsevier. https://doi.org/10.1016/j.transproceed.2006.08.084

Hintz, S. R., Bann, C. M., Ambalavanan, N., Cotten, C. M., Das, A., \& Higgins, R. D. (2010). Predicting time to hospital discharge for extremely preterm infants. Pediatrics, 125(1), e146-e154. https://doi.org/10.1542/peds.2009-0810

Ikatan Dokter Anak Indonesia. (2016). Konsensus Asuhan Nutrisi pada Bayi Prematur. 1st ed. Jakarta: Ikatan Dokter Anak Indonesia. 4-45.

Lee, H. C., Bennett, M. V., Crockett, M., Crowe, R., Gwiazdowski, S. G., Keller, H., ... \& Nisbet, C. C. (2018). Comparison of collaborative versus single-site quality improvement to reduce NICU length of stay. Pediatrics, 142(1). https://doi.org/10.1542/peds.2017-1395

Maier, R. F., Blondel, B., Piedvache, A., Misselwitz, B., Petrou, S., Van Reempts, P., ... \& van Heijst, A. (2018). Duration and time trends in hospital stay for very preterm infants differ across European regions. Pediatric critical care medicine, 19(12), 1153. https://dx.doi.org/10.1097\%2FPCC.0000000000001756

Manzoni, P., Stolfi, I., Pedicino, R., Vagnarelli, F., Mosca, F., Pugni, L., ... \& Borghesi, A. (2013). Human milk feeding prevents retinopathy of prematurity (ROP) in preterm VLBW neonates. Early human development, 89, S64-S68. https://doi.org/10.1016/S0378-3782(13)70019-7

Martins-Celini, F. P., Gonçalves-Ferri, W. A., Aragon, D. C., Bernichi, J. P., Calixto, C., Sacramento, E. M. F., ... \& Martinez, F. E. (2018). Association between type of feeding at discharge from the hospital and nutritional status of very low birth weight preterm infants. Brazilian Journal of Medical and Biological Research, 51(3). http://dx.doi.org/10.1590/1414-431x20176540

Namiiro, F. B., Mugalu, J., McAdams, R. M., \& Ndeezi, G. (2012). Poor birth weight recovery among low birth weight/preterm infants following hospital discharge in Kampala, Uganda. BMC pregnancy and childbirth, 12(1), 1. https://doi.org/10.1186/1471-2393-12-1

Quigley, M., Embleton, N. D., \& McGuire, W. (2019). Formula versus donor breast milk for feeding preterm or low birth weight infants. Cochrane Database of systematic reviews, (7). https://doi.org/10.1002/14651858.CD002971.pub5

Rani, P. J. (2017). Child labor among the tribal's: a study in kurnool district of andhra pradesh. International research journal of engineering, IT \& scientific research, 3(2), 76-84.

Wijaya, I. M. S., Sukmawati, M., Putra, P. J., Kardana, I. M., \& Artana, I. W. D. (2020). Nutritional status of preterm neonates at discharge in sanglah hospital. International Journal of Health Sciences, 4(3), 10-19. https://doi.org/10.29332/ijhs.v4n3.449 
Samra, N. M., El Taweel, A., \& Cadwell, K. (2013). Effect of intermittent kangaroo mother care on weight gain of low birth weight neonates with delayed weight gain. The Journal of perinatal education, 22(4), 194-200. https://doi.org/10.1891/1058-1243.22.4.194

Seaton, S. E., Barker, L., Jenkins, D., Draper, E. S., Abrams, K. R., \& Manktelow, B. N. (2016). What factors predict length of stay in a neonatal unit: a systematic review. BMJ open, 6(10), e010466.

Tang, M. L. K., Kemp, A. S., Hill, D. J., \& Thorburn, J. (1994). Reduced interferon- $\gamma$ secretion in neonates and subsequent atopy. The Lancet, 344(8928), 983-985. https://doi.org/10.1016/S0140-6736(94)91641-1

Uma, S., Nisha, S., \& Shikha, S. (2007). A prospective analysis of etiology and outcome of preterm labor. Journal of Obstetrics and Gynecology of India, 57(1), 48-52.

Utomo, M. T. (2010). Neonatal sepsis in low birth weight infants in Dr. Soetomo general hospital. Indonesian Journal of tropical and infectious disease, 1(2), 86-89. http://dx.doi.org/10.20473/ijtid.v1i2.2172

\section{Biography of Authors}

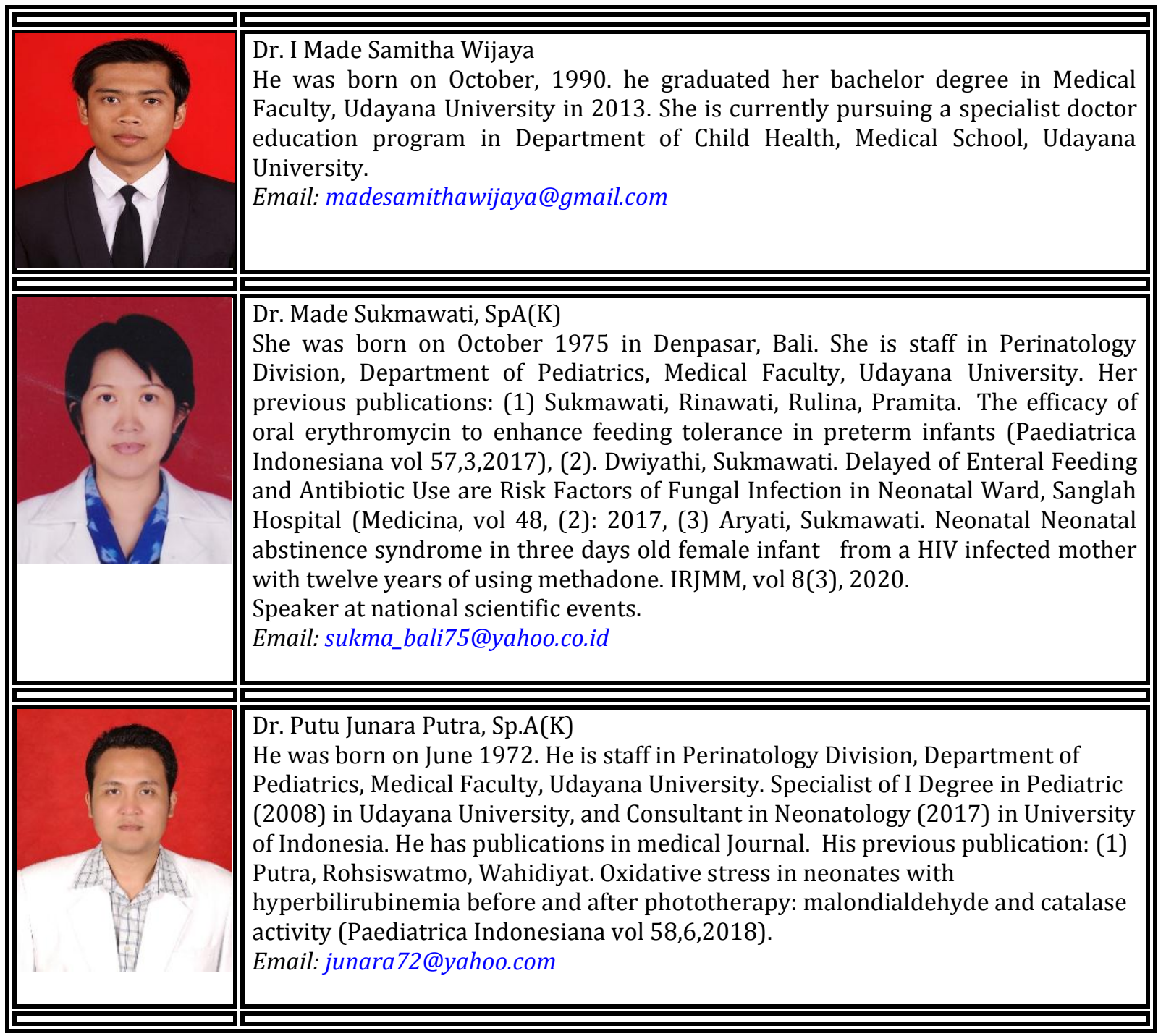




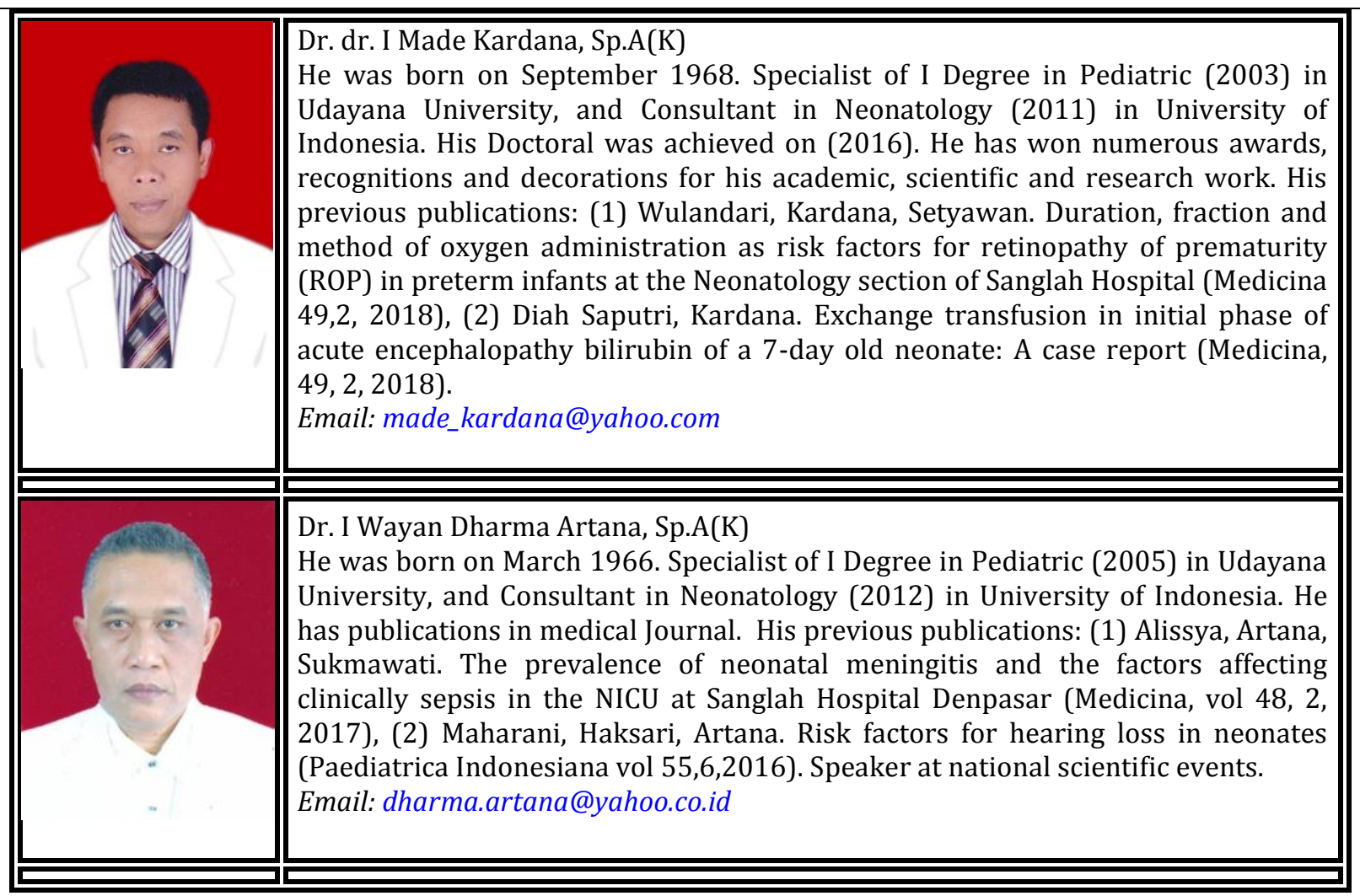

Wijaya, I. M. S., Sukmawati, M., Putra, P. J., Kardana, I. M., \& Artana, I. W. D. (2020). Nutritional status of preterm neonates at discharge in sanglah hospital. International Journal of Health Sciences, 4(3), 10-19. https://doi.org/10.29332/ijhs.v4n3.449 